\title{
In vitro Antioxidant Potential of Abrus precatorius L. and Asystasia gangetica (L.) T. Anderson
}

\author{
Narayanan Janakiraman ${ }^{1 \mathbb{D}}$, Marimuthu Johnson ${ }^{2 \mathbb{D}}$, Ray Silva Almeida ${ }^{3(\mathbb{D})}$, Henrique Douglas Melo \\ Coutinho $^{3, * \text { (D) }}$ \\ 1 Department of Botany, Madura College (Autonomous), Madurai - 625011 , Tamil Nadu, India; \\ biojanakiraman@gmail.com (N.J.); \\ 2 Centre for Plant Biotechnology, Department of Botany, St. Xavier's College (Autonomous), Palayamkottai - 627002 , \\ Tamil Nadu, India; ptcjohnson@gmail.com (M.J.); \\ 3 Laboratorio de Microbiologia e Biologia Molecular, Department of Chemistry Biological, University Regional do Cariri - \\ URCA, Crato CE, Brasil; hdmcoutinho@urca.br (H.D.M.C.); ray.almeida@urca.br (R.S.A.); \\ * Correspondence: hdmcoutinho@gmail.com (H.D.M.C.);
}

Scopus Author ID 35236795400

Received: 30.06.2021; Revised: 10.08.2021; Accepted: 15.08.2021; Published: 30.10.2021

\begin{abstract}
Antioxidant substances are an important part of human life as it plays a key role in nutraceuticals and also help to defend free radicals present in our body. The present study highlights the need to find potent natural antioxidants from medicinal plants. Different extracts of Abrus precatorius L. (Fabaceae) and Asystasia gangetica (L.) T. Anderson (Acanthaceae) were successively prepared using petroleum ether, benzene, chloroform, and ethanol. It was evaluated for antioxidant activities using various assays. Maximum extractable total phenolics and flavonoids were recorded in varied extracts of $A$. precatorius and A. gangetica. The extracts also showed efficient phosphomolybdenum reduction, reducing power activity, nitric oxide, and hydrogen peroxide radical scavenging properties. It is very clear from the results that the studied plants A. precatorius and $A$. gangetica have remarkable medicinal uses with extraordinary potential for pharmaceuticals. Further detailed studies will pave the way to promote natural drugs for health benefits.
\end{abstract}

Keywords: antioxidant; nutraceuticals; free radicals; pharmaceuticals.

(C) 2021 by the authors. This article is an open-access article distributed under the terms and conditions of the Creative Commons Attribution (CC BY) license (https://creativecommons.org/licenses/by/4.0/).

\section{Introduction}

Free radical is capable of independent existence because it contains unpaired electrons. This reacts with another molecule by taking or giving electrons and is involved in various pathological conditions [1]. Free radicals contribute to aging and degenerative diseases such as cancer, immune system decline, brain dysfunction, and cardiovascular disease [2, 3]. Antioxidants provide various useful compounds that control free radicals. Medicinal plants produce different secondary metabolites with antioxidant properties. Natural antioxidants in plant extracts protect the cells from oxidative damage and scavenge harmful free radicals in our bodies. The antioxidant activities of plants are linked with phenolic compounds, flavonoids, anthocyanins, and tannins. Numerous pieces of evidence by a large number of screening tests confirmed the in vitro antioxidant activities [4,5]. Epidemiological studies also revealed that antioxidant compounds possess various properties, including antitumor, analgesic, antiinflammatory, antimutagenic, anti-atherosclerotic, and antimicrobial [6, 7]. 
Abrus precatorius L. (Fabaceae), commonly known as Indian licorice, is a climbing shrub native to Indonesia. It grows in tropical and subtropical areas of the world and is distributed throughout India. Roots possess the diuretic activity and are also used in preparations prescribed for jaundice, haemoglobinuria, and gonorrhea [8]. Glycyrrhizin, the principal constituent of $A$. precatorius is used as a substitute for Glycyrrhiza glabra in catarrhal infections and cough [9]. Lectins isolated from A. precatorius contain immunostimulant properties [10]. The seeds of A. precatorius are used to treat arthritis, eye diseases, diabetes, jaundice, leucoderma, and poisonous bite in Siddha medicine [11].

Asystasia gangetica (L.) T. Anderson (Ganges Primrose) is a fast-growing herbaceous plant belonging to the family Acanthaceae. It is cosmopolitan in occurrence. The leaves contain huge amounts of proteins, minerals, lipids, and fibers. The plant is used ethnomedicinally to treat rheumatism, heart pain, vermifuge, and stomach pains [12]. Pharmacological studies confirmed that the leaves of A. gangetica contain anti-inflammatory and bronchospasmolytic properties. The leaves extract also inhibit histamine and serotonin-induced contractions of the guinea pig trachea [13]. With this background, the present study focuses on evaluating the antioxidant potential of $A$. precatorius and A. gangetica and their usage in various traditional systems of medicine.

\section{Materials and Methods}

\subsection{Collection of plant materials.}

Healthy plant specimens of Abrus precatorius L. (Fabaceae) and Asystasia gangetica (L.) T. Anderson (Acanthaceae) were collected from Marunthuvazhmalai, Kanyakumari District, Tamil Nadu, India. They were washed well initially with tap water to remove the adhered debris and then with distilled water. The plant samples were dried using blotting paper and kept at room temperature under shade for 15 days. The shade dried plant samples were ground to a fine powder using a mechanical grinder.

\subsection{Preparation of extracts.}

$30 \mathrm{~g}$ of airdried powder was extracted successively with $180 \mathrm{~mL}$ of solvents viz., petroleum ether, benzene, chloroform, and ethanol using soxhlet apparatus for $8 \mathrm{~h}$ at a temperature not exceeding the boiling point of the solvent. The extracts were frozen and freezedried.

\subsection{Determination of total phenolics.}

The total phenolic content present in A. precatorius and A. gangetica was determined according to the method described by Janakiraman and Johnson [14]. 100-200 $\mu \mathrm{L}$ aliquots were taken in test tubes and made up to $1 \mathrm{~mL}$ with distilled water. $0.5 \mathrm{~mL}$ of Folin-Ciocalteu reagent and $2.5 \mathrm{~mL}$ of sodium carbonate solution (20\%) were added to each tube. The reaction mixture was vortexed, and the test tubes were placed in the dark for $40 \mathrm{~min}$. The absorbance was noted at $725 \mathrm{~nm}$ against blank. The analysis was performed in triplicates, and the results were expressed as Gallic Acid Equivalents (GAE). 


\subsection{Estimation of total flavonoids.}

The flavonoid contents of various extracts of A. precatorius and A. gangetica were determined by the method described by Johnson et al. (2020) [15]. $500 \mu \mathrm{L}$ of extracts were taken in different test tubes. $2 \mathrm{~mL}$ of distilled water and $150 \mu \mathrm{L}$ of $5 \% \mathrm{NaNO}_{2}$ were added to all the test tubes. The tubes were incubated at room temperature for $6 \mathrm{~min}$. After incubation, $150 \mu \mathrm{L}$ of $\mathrm{AlCl}_{3}(10 \%)$ was added to all the test tubes, including blank. All the tubes were again incubated for $6 \mathrm{~min}$ at room temperature. Finally, $2 \mathrm{~mL}$ of $8 \% \mathrm{NaOH}$ was added, and it was made up to $5 \mathrm{~mL}$ using distilled water. The contents were vortexed well and allowed to stand for $15 \mathrm{~min}$ at room temperature. The absorbance was recorded at $510 \mathrm{~nm}$ using a spectrophotometer. The total flavonoid contents were expressed in GAE.

\subsection{Phosphomolybdenum assay.}

The antioxidant potential of $A$. precatorius and A. gangetica was evaluated using the green phosphomolybdenum complex formation [16]. Aliquots of $100 \mu \mathrm{L}$ extracts (in $1 \mathrm{mM}$ DMSO) were combined with $1 \mathrm{~mL}$ of reagent solution ( $0.6 \mathrm{M}$ sulphuric acid, $28 \mathrm{mM}$ sodium phosphate, and $4 \mathrm{mM}$ ammonium molybdate) in a $4 \mathrm{~mL}$ vial. The vials were sealed and incubated in a water bath at $95^{\circ} \mathrm{C}$ for $90 \mathrm{~min}$. The samples were cooled to room temperature. The absorbance was noted at $695 \mathrm{~nm}$ against a blank. The results are expressed as $\mathrm{g}$ of ascorbic acid (AA) equivalents / $100 \mathrm{~g}$ extract.

\subsection{Nitric oxide radical scavenging activity.}

The nitric oxide scavenging activity of various extracts of $A$. precatorius and $A$. gangetica on nitric oxide radical was measured using the standard method [17]. In phosphatebuffered saline, sodium nitroprusside $(10 \mathrm{mM})$ was mixed with different concentrations (50$250 \mu \mathrm{L}$ ) of plant extracts. It was incubated at room temperature for $150 \mathrm{~min}$. Griess reagent $(0.5 \mathrm{~mL})$, containing $1 \%$ sulphanilamide, $2 \% \quad \mathrm{H}_{3} \mathrm{PO}_{4}$, and $0.1 \% \quad \mathrm{~N}$-(1-naphthyl) ethylenediamine dihydrochloride was added to the mixture after incubation time. The absorbance of the formed chromophore was measured at $546 \mathrm{~nm}$. BHT and rutin were used as a positive and negative control. Radical scavenging activity was expressed as the inhibition percentage of free radical by the extracts. The percentage inhibition activity was calculated using the formula:

$\%$ radical scavenging activity $=[($ Control OD - Sample OD) $/$ Control OD $] \times 100$

\subsection{Scavenging of hydrogen peroxide.}

The ability of $A$. precatorius and $A$. gangetica extracts to scavenge hydrogen peroxide was determined according to the standard protocol [18]. 100-200 mg/mL extracts were added to hydrogen peroxide solution $(0.6 \mathrm{~mL}$ ) prepared in phosphate buffer ( $\mathrm{pH} 7.4$ ).After 10 minutes, the absorbance was recorded at $230 \mathrm{~nm}$ against a blank solution containing phosphate buffer without hydrogen peroxide. The percentage inhibition activity was calculated using the formula:

$\%$ scavenging activity $=[($ Control OD - Sample OD $) /$ Control OD $] \times 100$ 
2.8. Reducing power.

The reducing power of different extracts $A$. precatorius and A. gangetica was determined according to the standard method reported by Bhalodia et al. (2013)[19]. 20-100 $\mu \mathrm{L}$ of extracts were taken in $1 \mathrm{~mL}$ of phosphate buffer, and $5 \mathrm{~mL}$ of $0.2 \mathrm{M}$ phosphate buffer (pH 6.6) was added. To this, $5 \mathrm{~mL}$ of $1 \%$ potassium ferricyanide solution was added. The mixture was incubated at $50^{\circ} \mathrm{C}$ for $20 \mathrm{~min}$. After an appropriate incubation period, $5 \mathrm{~mL}$ of $10 \%$ trichloroacetic acid was added. The contents were centrifuged at $1000 \mathrm{rpm}$ for $10 \mathrm{~min}$. The upper layer of the supernatant $(5 \mathrm{~mL})$ was mixed with $5 \mathrm{~mL}$ of distilled water and $0.5 \mathrm{~mL}$ of $0.1 \%$ ferric chloride. The absorbance of the reaction mixture was noted using a spectrophotometer at $700 \mathrm{~nm}$.

\subsection{Statistical analysis.}

The results obtained from the different antioxidant assays were presented as triplicate determinations \pm standard deviation $(\mathrm{SD})$.

\section{Results and Discussion}

The total phenolic contents present in different extracts of A. precatorius and $A$. gangetica were presented in Table 1 . In A. precatorius, the maximum extractable total phenolics (419.04 mg GAE/g) were recorded in ethanolic extracts followed by chloroform and petroleum ether extracts. Benzene extracts gave the lowest level of total phenolics $(58.73 \mathrm{mg}$ GAE/g). In A. gangetica, the highest amount of total phenolic contents was observed in benzene extracts $(328.57 \mathrm{mg} \mathrm{GAE} / \mathrm{g})$, whereas petroleum ether and ethanolic extracts demonstrated a moderate level of phenolics. Chloroform extracts showed the minimum amount of phenolics (60.31 mg GAE/g). Phenolic compounds are one of the richest groups of secondary metabolites present in the plant kingdom [20]. It possesses antioxidant and free radical scavenging abilities, which potentially have numerous beneficial implications for human health [21]. Phenolic compounds act as natural antioxidants by helping to neutralize free radicals present in our body, and it was confirmed through various epidemiological studies. The multiple hydroxyl groups and their arrangement around the phenolic molecule help in scavenging free radicals [22, 23]. In the present study, the quantitative analysis determined the presence of phenolic compounds in all the four tested extracts of $A$. precatorius and $A$. gangetica. It suggests that the selected two plants are a promising source of effective antioxidants.

Table 1. Total Phenolics and Flavonoids present in A.precatorius and A. gangetica.

\begin{tabular}{l|c|c|c|c}
\multirow{2}{*}{ Extracts } & \multicolumn{2}{|c|}{ Phenolics $(\mathbf{m g}$ GAE/g \pm SD) } & \multicolumn{2}{c}{ Flavonoids (mg GAE/g \pm SD) } \\
\cline { 2 - 5 } & A. precatorius & A. gangetica & A. precatorius & A. gangetica \\
\hline Petroleum ether & $326.19 \pm 9.91$ & $217.46 \pm 5.49$ & $453.33 \pm 6.66$ & $160.00 \pm 17.63$ \\
\hline Benzene & $58.73 \pm 7.27$ & $328.57 \pm 12.59$ & $86.66 \pm 13.33$ & $104.44 \pm 13.87$ \\
\hline Chloroform & $361.90 \pm 12.59$ & $60.31 \pm 7.27$ & $342.22 \pm 16.77$ & $302.22 \pm 3.84$ \\
\hline Ethanol & $419.04 \pm 4.76$ & $139.68 \pm 7.27$ & $153.33 \pm 6.66$ & $237.77 \pm 10.18$
\end{tabular}

Table 2. Phosphomolybdenum assay of A. precatorius and A. gangetica.

\begin{tabular}{l|c|c} 
Extracts & A. precatorius & A. gangetica \\
\hline Petroleum Ether & $60.3 \pm 2.3$ & $4.1 \pm 0.6$ \\
\hline Benzene & $20.2 \pm 1.1$ & $21.0 \pm 1.3$ \\
\hline Chloroform & $25.5 \pm 1.7$ & $13.1 \pm 1.7$ \\
\hline Ethanol & $65.9 \pm 0.6$ & $53.9 \pm 1.1$
\end{tabular}


Table 3. NO radical scavenging activity of $A$. precatorius and $A$. gangetica.

\begin{tabular}{l|c|c} 
Extracts & A. precatorius & A. gangetica \\
\hline Petroleum Ether & $53.4 \pm 1.46$ & $55.3 \pm 2.23$ \\
\hline Benzene & $87.9 \pm 0.84$ & $75.2 \pm 1.46$ \\
\hline Chloroform & $82.0 \pm 2.23$ & $81.5 \pm 3.03$ \\
\hline Ethanol & $67.4 \pm 1.68$ & $92.2 \pm 0.84$
\end{tabular}

Table 4. $\mathrm{H}_{2} \mathrm{O}_{2}$ scavenging activity of A. precatorius and A. gangetica.

\begin{tabular}{l|c|c} 
Extracts & A. precatorius & A. gangetica \\
\hline Petroleum Ether & $94.8 \pm 0.4$ & $96.3 \pm 0.4$ \\
\hline Benzene & $75.8 \pm 1.3$ & $81.7 \pm 0.7$ \\
\hline Chloroform & $90.8 \pm 0.6$ & $88.3 \pm 0.6$ \\
\hline Ethanol & $96.8 \pm 0.2$ & $61.0 \pm 0.2$
\end{tabular}

Total flavonoid contents of various extracts of A. precatorius varied considerably from 86.66 to $453.33 \mathrm{mg} \mathrm{GAE} / \mathrm{g}$ extract. The highest amount of flavonoids ( $453.33 \mathrm{mg} \mathrm{GAE} / \mathrm{g}$ ) were present in petroleum ether extracts, followed by chloroform and ethanolic extracts. Among the different extracts analyzed in A. gangetica, the flavonoids content was found to be maximum (302.22 mg GAE/g) in chloroform extracts, whereas the other extracts showed a moderate level of flavonoids (Table 1). Flavonoids are the broadly distributed group of plant phenolic compounds, and it acts as an effective antioxidant [24]. Flavonoids are responsible for protecting plants against various stresses. It helps in the interaction between the plant and its environment and plays an important role in exhibiting a variety of biological functions [25]. Flavonoids are not essential for the survival of the plant. They are biologically active and assist in the transport of auxin [26]. Flavonoids are responsible for the color of the flower, and they also protect plants against microorganisms and insects. Flavonoids are attractants to pollinators. It protects plants against harmful ultraviolet radiation and helps signal molecules to facilitate nitrogen fixation $[27,28]$. They are well recognized for their antioxidant effects, protecting the body from various diseases [29]. The presence of a varied degree of flavonoids in different extracts of $A$. precatorius and A. gangetica confirmed the antioxidative effects with various health beneficiary aspects.

The reduction of Mo (VI) to green phosphate in phosphomolybdenum is due to antioxidant compounds. The results of phosphomolybdenum assay of $A$. precatorius and $A$. gangetica extracts are illustrated in Table 2. Among the various extracts of A. precatorius, ethanolic extracts showed the strongest phosphomolybdenum reduction (65.9 g AA/100 g), followed by petroleum ether extracts $(60.3 \mathrm{~g} \mathrm{AA} / 100 \mathrm{~g})$. Chloroform and benzene extracts showed the minimum level of phosphomolybdenum reduction in A. precatorius. In $A$. gangetica, ethanolic extracts registered the highest phosphomolybdenum reduction $(53.9 \mathrm{~g}$ $\mathrm{AA} / 100 \mathrm{~g})$, followed by a reasonable reduction of benzene extract $(21.0 \mathrm{~g} \mathrm{AA} / 100 \mathrm{~g})$. Chloroform and petroleum ether extracts demonstrated a minor level of reduction. Phosphomolybdenum essay is very simple and independent of other antioxidant assays due to its varied application to plant extracts [18]. Electron transfer from antioxidants to Mo (VI) complex occurs in phosphomolybdenum assay. This reduction ability was observed in extracts of $A$. precatorius and A. gangetica.

The nitric oxide radical scavenging activity was determined using Griess reagent. The amount of nitrous acid will decrease in the presence of a plant extract, and it can be measured at $546 \mathrm{~nm}$. The nitric oxide radical scavenging activity of different extracts of A. precatorius and $A$. gangetica is shown in Table 3. In A. precatorius, higher NO radical scavenging activity was observed in benzene extracts $(87.9 \%)$, followed by chloroform and ethanolic extracts $(82.0$ and $67.4 \%$ ), respectively. Petroleum ether extracts showed the lowest percentage $(53.4 \%)$ of 
free radical scavenging activity in A. precatorius. The ethanolic extracts of $A$. gangetica exhibited a maximum percentage $(92.2 \%)$ of $\mathrm{NO}$ radical scavenging activity, followed by chloroform and benzene extracts ( 81.5 and $75.2 \%$, respectively). The lowest percentage (55.3\%) was observed in petroleum ether extracts of A. gangetica. The results indicate that all the extracts are expected to have this ability. Nitric oxide is formed from L-arginine by the activity of nitric oxide synthase. Nitric oxide depletes the concentration of ascorbic acid and initiates lipid peroxidation when it is exposed to human blood plasma. Nitric oxide is also responsible for cancer, inflammation, and various pathological conditions [30]. Jung et al. (2009)[31] performed antioxidant activity using nitric oxide assay in Brassica juncea, and the results showed noticeable activity against the radical. Similar to the previous observations, the inhibition shown by the benzene extracts of $A$. precatorius and ethanolic extracts of $A$. gangetica can have a significant role in scavenging nitric oxide radical.

The extracts of $A$. precatorius and A. gangetica showed an efficient $\mathrm{H}_{2} \mathrm{O}_{2}$ scavenging potential (Table 4). Among the extracts of $A$. precatorius, ethanolic extracts showed maximum inhibition (96.8\%), followed by petroleum ether and chloroform extracts (94.8 and 90.8\%, respectively). In $A$. gangetica, petroleum ether extracts exhibited the highest inhibition percentage $(96.3 \%)$, followed by chloroform and benzene extracts $(88.3 \%$ and $81.7 \%)$, respectively. The results of $\mathrm{H}_{2} \mathrm{O}_{2}$ scavenging activity indicate that the extracts could act as an effective scavenger of hydrogen peroxide. $\mathrm{H}_{2} \mathrm{O}_{2}$ can be converted to a more reactive hydroxyl radical, which is one of the unfavorable effects caused by it [32]. The results showed that $A$. precatorius and A. gangetica could act as a good scavenger of hydrogen peroxide.

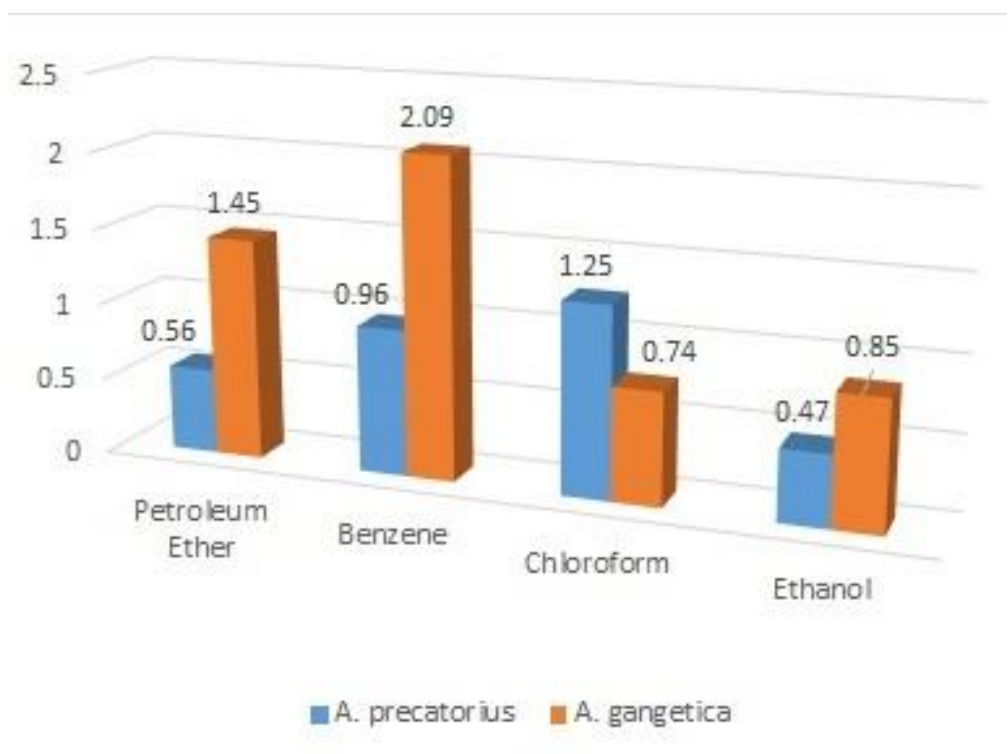

Figure 1. Reducing power activity of A. precatorius and A. gangetica.

The reducing property is related to the presence of reductants. The antioxidant property of reductants is based on the breakage of the free radical chain by donating a hydrogen atom. The reducing power of different extracts of A. precatorius and A. gangetica was illustrated in Fig. 1. A strong reducing power was observed in benzene extracts of $A$. gangetica followed by petroleum ether extract. In $A$. precatorius, maximum reducing power was seen in chloroform extracts. The data presented here clearly indicate the marked reducing potential of the tested extracts due to the presence of phenolic compounds, which act as reductants by donating the electrons. It reacts with free radicals and terminates radical chain reaction. 
Pal et al. (2009) [33] screened the seed extracts of A. precatorius for their potential antioxidant activities using hydroxyl radical, reducing power and hydrogen peroxide scavenging activity. The results showed potent antioxidant activity when compared with the reference compound butylated hydroxyl toluene (BHT). Akula and Odhav (2008)[34] studied the DPPH radical scavenging activity of A. gangetica and found that methanolic extracts were more effective DPPH radical scavengers than the aqueous extracts. Reddy et al. (2012) [35] studied the methanolic extract of A. gangetica for potent antioxidant properties using different in vitro models. It possesses potent DPPH radical scavenging activity and reducing power effects. Similar to the previous observations, the present study results depicted the free radical scavenging properties of different extracts of A. precatorius and A. gangetica, which may be due to the presence of phenols and flavonoids.

\section{Conclusion}

The results showed a clear indication that the extracts of A. precatorius and A. gangetica have widespread use as antioxidants. These findings also justify that these plants are an easily accessible source of natural antioxidants, which can be used as a dietary supplement in nutraceutical and pharmaceutical products. Further studies are needed to isolate the bioactive compounds from these plants, and it will surely pave the way for promoting natural drugs for treating diseases.

\section{Funding}

This research received no external funding.

\section{Acknowledgments}

This research has no acknowledgment.

\section{Conflicts of Interest}

The authors declare no conflict of interest.

\section{References}

1. Jagessar, R.C. Antioxidant properties of plant extracts. Edelweiss Pharma Analytic Acta. 2019,1, 1821,https://doi.org/10.33805/2689-9477.105.

2. Mishra, J.; Srivastava, R.K.; Shukla, S.V.; Raghav, C.S. Antioxidants in Aromatic and Medicinal plants.Science Tech Entrepreneur.2007, 1-16.

3. Stanner, S.A.; Hughes, J.; Kelly, C.N.M.; Buttriss, J. A review of the epidemiological evidence for the 'antioxidant hypothesis'. Public Health Nutrition 2004, 7, 407-422,https://doi.org/10.1079/phn2003543.

4. Senhaji, S.; Lamchouri, F.; Toufik, H. Phytochemical content, antibacterial and antioxidant potential of endemic plant Anabasis aretioides Coss. \& Moq. (Chenopodiaceae). Biomed Res Int. 2020, https://doi.org/10.1155/2020/6152932.

5. Unuofin, J.O.; Lebelo, S.L. Antioxidant Effects and Mechanisms of Medicinal Plants and Their Bioactive Compounds for the Prevention and Treatment of Type 2 Diabetes: An Updated Review. Oxidative Medicine and Cellular Longevity 2020, 2020,https://doi.org/10.1155/2020/1356893.

6. Merghem, M.; Dahamna, S.; Khennouf, S. In vivo antioxidant activity of Rutamontana L. extracts. J Mater Environ Sci2019, 10, 470-477.

7. Tung, Y.-T.; Wu, J.-H.; Huang, C.-Y.; Kuo, Y.-H.; Chang, S.-T. Antioxidant activities and phytochemical characteristics of extracts from Acacia confusa bark. Bioresource Technology 2009, 100, 509-514, https://doi.org/10.1016/j.biortech.2008.01.001.

8. Mistry, K.; Mehta, M.; Mendpara, N.; Gamit, S.; Shah, G. Determination of antibacterial activity and MIC of crude extract of Abrus precatorius L. Adv Biotechnol2010, 10, 25-27. 
9. Bolou, G.E.K.; Bagre, I.; Ouattara, K.; Djaman, A.J. Evaluation of the antibacterial activity of 14 medicinal plants in Cote d'Ivoire. Trop J Pharml Res2011, 10, 335-340,https://doi.org/10.4314/tjpr.v10i3.3.

10. Bhutia, S.K.; Mallick, S.K.; Maiti, T.K. In vitro immunostimulatory properties of Abrus lectins derived peptides in tumor bearing mice. Phytomedicine 2009, 16, 776-782, https://doi.org/10.1016/j.phymed.2009.01.006.

11. Ayyanar, M.; Singarasivaraman, K.; Ignacimuthu, S. Traditional herbal medicines used for the treatment of diabetes among two major tribal groups in South Tamilnadu, India. Ethnobot Leaflets 2008,12, 276-280.

12. Elliot, L. Asystasia gangetica (L.) T. Anderson. subsp. micrantha (Nees). National Biodiversity Institute, South Africa 2004.

13. Akah, P.A.; Ezike, A.C.; Nwafor, S.V.; Okoli, C.O.; Enwerem, N.M. Evaluation of the anti-asthmatic property of Asystasia gangetica leaf extracts. Journal of Ethnopharmacology 2003, 89, 25-36, https://doi.org/10.1016/s0378-8741(03)00227-7.

14. Janakiraman, N, Johnson, M. In vitro antioxidant properties of natural products isolated from selected species of Cyathea. J Clin Nephrol Res2015,2.

15. Johnson, M.A.; Madona, C.X.; Almeida, R.S.; Martins, N.; Coutinho, H.D.M. In Vitro Toxicity, Antioxidant, Anti-Inflammatory, and Antidiabetic Potential of Sphaerostephanos unitus (L.) Holttum. Antibiotics 2020, 9 , https://doi.org/10.3390/antibiotics9060333.

16. Prieto, P.; Pineda, M.; Aguilar, M. Spectrophotometric Quantitation of Antioxidant Capacity through the Formation of a Phosphomolybdenum Complex: Specific Application to the Determination of Vitamin E. Analytical Biochemistry 1999, 269, 337-341,https://doi.org/10.1006/abio.1999.4019.

17. Sreejayan; Rao, M.N.A. Nitric Oxide Scavenging by Curcuminoids. Journal of Pharmacy and Pharmacology 1997, 49, 105-107,https://doi.org/10.1111/j.2042-7158.1997.tb06761.x.

18. Fernando, C.D.; Soysa, P. Optimized enzymatic colorimetric assay for determination of hydrogen peroxide $\left(\mathrm{H}_{2} \mathrm{O}_{2}\right)$ scavenging activity of plant extracts. Methods X2015, 2, 283291,https://doi.org/10.1016/j.mex.2015.05.001.

19. Bhalodia, N.R.; Nariya, P.B.; Acharya, R.N.; Shukla,V.J. In vitro antioxidant activity of hydro alcoholic extract from the fruit pulp of Cassia fistula Linn. Ауи 2013, 34, 209-214,https://doi.org/10.4103/09748520.119684 .

20. Janakiraman, N.; Johnson, M. HPTLC fingerprint profile (Phenolics) of selected Cyathea species from Western Ghats, South India. Chinese J Biol2016, 2016, 1-7,https://doi.org/10.1155/2016/6420371.

21. Govindarajan, R.; Singh, D.P.; Rawat, A.K.S. High-performance liquid chromatographic method for the quantification of phenolics in 'Chyavanprash' a potent Ayurvedic drug. JPharmBiomedAnal2007, 43, 527532,https://doi.org/10.1016/j.jpba.2006.08.005.

22. Moyo, M.; Ndhlala, A.R.; Finnie, J.F.; Van Staden, J. Phenolic composition, antioxidant and acetylcholinesterase inhibitory activities of Sclerocarya birrea and Harpephyllum caffrum (Anacardiaceae) extracts. Food Chem.2010, 123, 69-76.

23. Muchuweti, M.; Ndhlala, A.R.; Kasiyamhuru, A. Analysis of phenolic acids including tannins, gallotanins and flavonols in Uapaca kirkiana fruits. Food Chem2006, 94, 415419,https://doi.org/10.1016/j.foodchem.2004.11.030.

24. Yanishlieva-Maslarova, N.V. Inhibiting oxidation. In: Antioxidants in food: Practical applications.Pokorny, J.; Yanishlieva, N.; Gordon, M.H. editors. Cambridge: Wood Head Publishing Ltd, 2001; pp. 22-70.

25. Pourcel, L.; Routaboul, J.M.; Cheynier, V. Flavonoid oxidation in plants: from biochemical properties to physiological functions. Trends Plant Sci2007, 12, 29-36,https://doi.org/10.1016/j.tplants.2006.11.006.

26. Buer, C.S.; Imin, N.; Djordjevic, M.A. Flavonoids: New roles for old molecules. J Integr Plant Biol. 2010 , 52, 98-111,https://doi.org/10.1111/j.1744-7909.2010.00905.x.

27. Griesbach, R.J. Biochemistry and genetics of flower color. Plant Breed Rev. 2005, 25, 89-114.

28. Yao, L.H.; Jiang, Y.M.; Shi, J. Flavonoids in food and their health benefits. Plant Food Hum Nutr2004, 59, 113-122,https://doi.org/10.1007/s11130-004-0049-7.

29. Nijveldt, R.J.; van Nood, E.; van Hoorn, D.E.; Boelens, P.G.; van Norren, K.; van Leeuwen, P.A. Flavonoids: a review of probable mechanisms of action and potential applications. Am J Clin Nutr.2001, 74, 418425,https://doi.org/10.1093/ajcn/74.4.418.

30. Fang, Y.Z.; Yang, S.; Wu, G. Free radicals, antioxidants and nutrition. Nutrition2002, 18, 872-879, https://doi.org/10.1016/s0899-9007(02)00916-4.

31. Jung, H.A.; Woo, J.J.; Jung, M.J.; Hwang, G.S.; Choi, J.S. Kaempferol glycosides with antioxidant activity from Brassica juncea. ArchPharmRes. 2009, 32, 1379-1384,https://doi.org/10.1007/s12272-009-2006-3.

32. Yen, F.L.; Wu, T.H.; Lin, L.T.; Cham, T.M.; Lin, C.C. Concordance between antioxidant activities and flavonol contents in different extracts and fractions of Cuscuta chinensis. FoodChem2008, 108, 455462,https://doi.org/10.1016/j.foodchem.2007.10.077.

33. Pal, R.S.; Ariharasivakumar, G.; Girhepunje, K.; Upadhyay, A. In vitro antioxidative activity of phenolic and flavonoid compounds extracted from seeds of Abrus precatorius. Int J Pharm Pharm Sci. 2009, 1, 136-140.

34. Akula, U.S.; Odhav, B. In vitro 5-Lipoxygenase inhibition of polyphenolic antioxidants from undomesticated plants of South Africa. J Med Plants Res2008, 2, 207-212. 
35. Reddy, N.V.L.S.; Anarthe, S.J.; Raghavendra, N.M. In vitro antioxidant and antidiabetic activity of Asystasia gangetica (Chinese Violet) Linn. (Acanthaceae). Int J Res Pharm Biomed Sci. 2012, 1, 72-75. 